\title{
Variation in the helminth community structure in bank voles (Clethrionomys glareolus) from three comparable localities in the Mazury Lake District region of Poland
}

\author{
J. M. BEHNKE ${ }^{1 *}$, C. J. BARNARD ${ }^{1}$, A. BAJER ${ }^{2}$, D. BRAY ${ }^{1}$, J. DINMORE ${ }^{1}, \mathrm{~K} \mathrm{FRAKE}^{2}$, \\ J. OSMOND ${ }^{1}$, T. RACE ${ }^{1}$ and E. SINSKI ${ }^{2}$ \\ ${ }^{1}$ School of Life and Environmental Sciences, University of Nottingham, University Park, Nottingham NG7 2RD, UK \\ ${ }^{2}$ Department of Parasitology, Institute of Zoology, University of Warszawa, ul. Miecznikowa 1, 02-096, Warszawa, \\ Poland
}

(Received 23 March 2001; revised 12 May 2001 ; accepted 12 May 2001)

S UM M A R Y

We tested the null hypothesis that populations of hosts trapped in isolated neighbouring locations showing comparable habitat quality, should support similar helminth parasite communities. The study was undertaken in a 2-week period in late summer in NE Poland in a single year, thereby eliminating seasonal and between-year variation in parasite burdens. A total of 139 Clethrionomys glareolus (bank vole) were sampled from 3 forest sites of similar habitat quality. Total species richness was 11 (6 nematodes and 5 cestodes) with $85.6 \%$ of the voles carrying at least 1 species and an overall mean species richness of $1 \cdot 4$. At the component community level, the fewest species of helminths were recorded from site 2 ( $n=6$, compared with 9 at each of the other sites), but site 3 had the lowest Berger-Parker Dominance Index and the highest Simpson's Index of Diversity. At the infracommunity level, site 3 had the highest mean no. of helminth species/vole, the highest mean Brillouin's Index of Diversity but the lowest mean no. of helminths/vole. Voles from sites 1 and 3 differed in the nematodes that were most common (site 1, Heligmosomum mixtum - 95\%; site 3, Heligmosomoides glareoli-79.3\%). At site 2 no species exceeded $50 \%$ but prevalence of Syphacia petrusewiczi was higher than at the other sites. The prevalence of cestodes was too low to test reliably $(12.9 \%)$, but the highest prevalence of adult cestodes was recorded at site 1 (22.5\% compared with 4.9 and $1.7 \%$ for sites 2 and 3 respectively). Host sex did not influence infection, but mean species richness increased with age. The different sites were responsible for most of the variation in our data, and the intrinsic factors (sex and age) were less important in shaping the component community structure of helminths. We conclude that even locations in relative close proximity to one another $(13-25 \mathrm{~km})$, selected on the basis of similar habitat quality, have rodent populations that differ in their helminth parasite communities, although for reasons other than the factors quantified in the present study.

Key words: bank vole, Clethrionomys glareolus, helminths, nematodes, cestodes, component community, site-specific variation.

\section{INTRODUCTION}

Parasitic infections are being increasingly recognized as a major factor influencing host behaviour, lifehistory strategies and population dynamics (Sheldon \& Verhulst, 1996; Hillgarth \& Wingfield, 1997; Hudson \& Dobson, 1997; Barnard \& Behnke, 2001). Fragmentation of the environment by natural barriers (e.g. lakes, mountain ranges) and/or human activities (e.g. towns, major roads, agriculture) can lead to isolated subpopulations of hosts (Hanski, 1997). Such subpopulations may be subject to different selection pressures created by local conditions, with profound implications for the dynamics of the overall population. Local differences in

* Corresponding author: School of Life and Environmental Sciences, University of Nottingham, University Park, Nottingham NG7 2RD, UK. Tel: +44(0) 115951 3208. Fax: +44(0) 115951 3251. E-mail: jerzy.behnke@nottingham.ac.uk parasite communities infecting subpopulations are likely to create one important source of variation in selection pressure.

The structure of helminth component communities in wild rodents in Europe has been well documented and is known to be affected by both extrinsic (year, season etc.) and intrinsic (host age, sex) factors (Montgomery \& Montgomery, 1990; Behnke et al. 1999; Abu-Madi et al. 2000). Perhaps surprisingly intrinsic factors have generally been found to play a lesser role in shaping these communities than extrinsic factors: host sex has rarely been found to contribute significantly (Kisielewska, 1970c; O'Sullivan, Small \& Fairley, 1984; AbuMadi et al. 2000), although there are some reports of particular species showing a significant sex bias (Lewis, 1968; Behnke et al. 1999). Accurate estimation of the age of wild rodents is notoriously difficult (Morris, 1972) but nevertheless, employing relatively crude measures of age e.g. body weight or 
eye lens weight, a significant role for host age in structuring component communities has been identified. Young animals will have had less opportunity to encounter infective stages than adults, and since many rodent helminths cause chronic infections, worm burdens and mean species richness accumulate with time and hence age of host (Haukisalmi, Henttonen \& Tenora, 1988; Montgomery \& Montgomery, 1989; Gregory, 1992; Behnke et al. 1999).

Extrinsic factors exert the most important influence on helminth communities with strong evidence in support of temporal variation arising through seasonal and annual changes in mean species richness (Langley \& Fairley, 1982; Haukisalmi et al. 1988; O'Sullivan et al. 1984; Montgomery \& Montgomery, 1989). Marked differences have also been reported in the structure of helminth component communities from rodents captured in different sites within similar climatic zones (Kisielewska, 1970c; Montgomery \& Montgomery, 1990; Abu-Madi et al. 2000), although to date few studies have systematically examined and compared helminth component communities from relatively isolated populations living in comparable habitats within close proximity to each other. Rather, the emphasis has been to select habitats of contrasting habitat quality (Montgomery \& Montgomery, 1990; Abu-Madi et al. 2000), despite the inevitable difficulties of interpretation in the absence of clear baseline values on the extent of natural variation in helminth communities when habitat quality remains constant (Kennedy, Hartvigsen \& Halvorsen, 1991 ; Hartvigsen \& Kennedy, 1993).

The study reported in this paper was based in Mazury in north-eastern Poland, a region rich in managed forests, interspersed with numerous lakes (in excess of 1000), rivers and canals that impede free movement of rodents between forest patches, and in some cases may create impassable barriers. Numerically the dominant woodland rodent is the bank vole, Clethrionomys glareolus, the ecology and population dynamics of which have been well documented over the years in Poland and elsewhere (Kozakiewicz, 1976a; Alibhai \& Gipps, 1985). Moreover, the east European parasite fauna of bank voles is also well known as a result of the extensive studies of Kisielewska $(1970 a, b, c)$ and others (Zarnowski, 1955), although advances in our understanding of the taxonomy of bank vole helminths have resulted in changes to the nomenclature of several of the species reported by these earlier workers (Haukisalimi \& Tenora, 1993; Tenora \& Meszaros, 1975; Wiger, Barus \& Tenora, 1978; Genov \& Yanchev, 1981).

We selected 3 study sites, within an extensive area of fragmented forest. The sites were chosen on the basis of the similarity of their habitat structure and type, and isolation from one another. Trapping was restricted to a single season in one year to eliminate other quantifiable extrinsic factors and hence the only known extrinsic factor in our study, at this time of year, was site of capture. We tested the null hypothesis that the composition of helminth component communities of the bank vole $C$. glareolus should not differ significantly between host populations living in habitats of similar quality.

\section{MATERIALS AND METHODS}

\section{Study sites}

Our study sites were located in Mazury in the north eastern corner of Poland, in the vicinity of the largest lake in the region, Jezioro Śniardwy and the towns of Mikołajki, Orzysz and Pisz (Fig. 1). Site 1 was located east of the nature reserve surrounding Lake Luknajno, and north of Lake Śniardwy (long. $21^{\circ} 39 \cdot 6^{\prime}$, lat $53^{\circ} 47 \cdot 7^{\prime}$, Leśnistwo Luknajno). Site 2 was located $13.5 \mathrm{~km}$ north-east of site 1 , on the eastern side of Lake 'Tałty (long. $21^{\circ} 32 \cdot 4^{\prime}$, lat $53^{\circ} 53 \cdot 5^{\prime}$, Leśnistwo Skorupki) and site 3 was located $11.5 \mathrm{~km}$ southeast of site 1 , on the eastern side of Lake Śniardwy (long. $21^{\circ} 48 \cdot 8^{\prime}$, lat $53^{\circ} 42 \cdot 3^{\prime}$, Leśnistwo Lisiej Jamy). All 3 sites were chosen on the basis of their similar habitat quality. All were mature woodlands with Scots pine (Pinus sylvestris) and silver birch (Betula verucosa) as the dominant trees but contained patches of dense Norway spruce (Picea abies), occasional oaks (Quercus robur), and common alders (Alnus glutinosa). The trees formed a high canopy over most of the area on each site and the shrub layer comprised mostly hazel (Corylus avellana). Ground cover comprised Oxalis acetosela, Convalaria mayalis and Stelaria holostea and in places dense patches of moss. There were several small woodland glades dominated by various grasses. The area occupied by the sites ranged over approximately 900-1200 hectares and each had one boundary comprising a lake shore but was otherwise surrounded by open agricultural land.

Comparability of the habitat structure was tested by taking line transects along each trapline and scoring the vegetation every $5 \mathrm{~m}$. At each sample point, the nearest item of vegetation (a) vertically above the observer, (b) $1 \mathrm{~m}$ to the left and $1 \mathrm{~m}$ to the right at a height of $1.2 \mathrm{~m}$ from the ground and (c) on the ground itself was recorded as: (i) high canopy (tree tops constituting the highest vegetation layer at the site), (ii) mid-canopy (tree tops below the high canopy), (iii) shrub (shrubs, bushes and immature trees up to $5 \mathrm{~m}$ in height), (iv) the trunk or branch of a high or mid-canopy tree), (v) tall herb (dicotyledonous plants over $1 \mathrm{~m}$ in height), (vi) herb (herb layer monocotyledonous and dicotyledonous plants), (vii) leaf litter and shed conifer needles and (viii) bare soil. The scores were then used to calculate the 


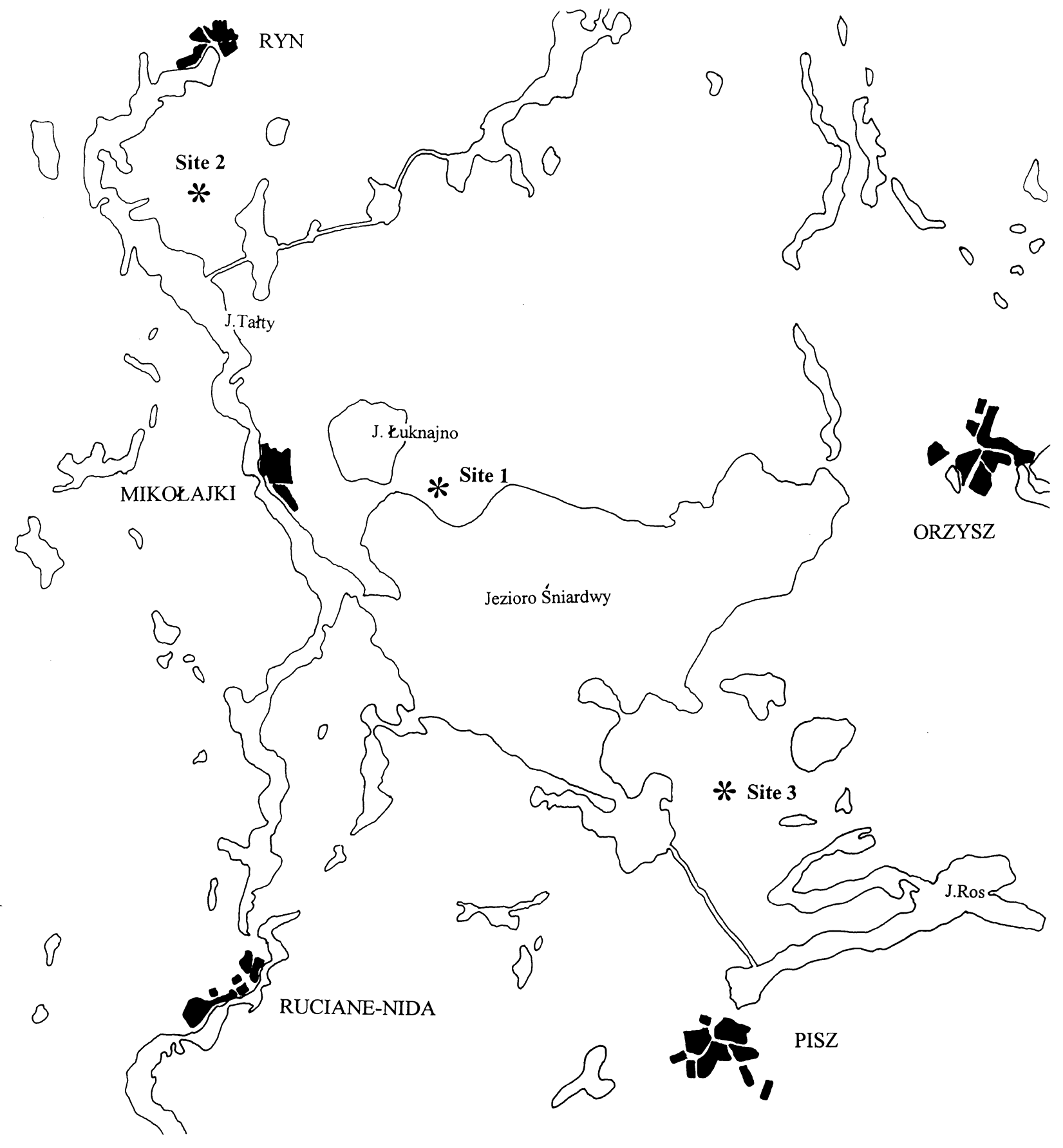

$10 \mathrm{~km}$

Fig. 1. Map of the region where trapping took place, showing the location of the 3 study sites in relation to local towns (areas filled in) and bodies of water (open areas), including canals.

percentage occurrence of each vegetation category $(0-100 \%$ in each case) at the sample points along each trapline.

\section{Collection of voles}

At each site, rodents were caught live in Longworth, Sherman or locally constructed wooden traps, with a small metal platform internally which when triggered released a metal door. Approximately 100 traps were used in total. These were set out at $20 \mathrm{~m}$ intervals in parallel lines, $10 \mathrm{~m}$ either side of tracks running through the sites and 2 traps were placed within $2-3 \mathrm{~m}$ of one another at each point. Trapping sessions comprised 4 days at each site with traps being inspected in the early morning and just before dusk. Any traps containing animals were replaced by fresh traps and the animals were brought to the University of Warszawa's field stations at Urwitalt (sites 1 and 2) or Pilchy (site 3). 


\section{Sampling of hosts}

At the field stations, all animals were identified, culled, weighed (to the nearest $0.1 \mathrm{~g}$ ), sexed and relevant morphometric data were recorded. Finally, the entire alimentary tract was removed, placed in plastic universals containing $10 \%$ formalin and the livers, lungs and body cavity were inspected for helminths.

Three age classes were established primarily on the basis of the combined dry weight of each vole's pair of eye lenses (Morris, 1971) as follows: juveniles (lens weight $=3-5 \mathrm{mg}$ ), young adult $(5 \cdot 1-5 \cdot 9 \mathrm{mg})$, mature adults $(\geqslant 6 \cdot 0 \mathrm{mg})$. These categories correspond approximately to voles $<63$, 63-100 and $>100$ days old (Kozakiewicz, 1976b). However, adjustments were made, particularly at the limits of each category, using other morphometric measurements which included the following parameters: visual assessment of maturity at capture (juvenile/ adult), externally apparent testes (scrotal/non-scrotal), pregnancy and lactation, head length, head width, nose-anal length, tail length and foot length. To confirm that age-related factors showed the predicted increase from age class 1 through to age class 3 we carried out 2-way analyses of variance with each of these measurements in turn as the dependent variable, and the 3 age classes and sex as the factors. All tests confirmed highly significant effects of age class (Fig. 2), but in the case of body weight, nose-anal and total body + tail length there were also significant differences between the sexes and significant interactions between sex and age class.

\section{Measures of community structure}

Following the report by Kennedy \& Hartvigsen (2000), measures of component community structure were total number of helminth species, the BergerParker Dominance Index and Simpson's Index of Diversity (unbiased as $(1-D) \times(n / n-1)$ where $n=$ total number of helminths in the sample and $D=$ Simpson's Index; Washington, 1984) for each site in turn. Infracommunity structure was assessed by mean number of helminth species per vole, maximum number of helminths and species density distribution across the sample, mean number of helminth individuals per vole, mean Brillouin's Index per vole (infected and uninfected), maximum Brillouin's Index, mean abundance and prevalence of individual species.

\section{Statistical analysis}

The frequency distribution of infracommunity species richness was tested for goodness of fit to the positive binomial distribution (assumption of the null model is a regular distribution), the Poisson distribution (assumption of the null model is a random distribution), the negative binomial model (assumption of the null model is an aggregated distribution) and the null model of Janovy et al. (1995) (assumption of the null model is that, in the absence of associations and interactions between species, the frequency distribution of infracommunity species richness is predicted by prevalence values of all the species comprising the component community). All distributions were tested for goodness of fit by $\chi^{2}$.

Prevalence data (percentage of animals infected) are shown with $95 \%$ confidence limits, calculated as described by Rohlf \& Sokal (1995). Prevalence was analysed by maximum likelihood techniques based on $\log$ linear analysis of contingency tables using the software package Statgraphics Version 7. Beginning with the most complex model, involving all possible main effects and interactions, those combinations which did not contribute significantly to explaining variation in the data were eliminated in a stepwise fashion beginning with the highest-level interaction. A minimum sufficient model was then obtained, for which the likelihood ratio of $\chi^{2}$ was not significant, indicating that the model was sufficient in explaining the data.

Summary figures for parasite abundance are expressed as arithmetic means \pm s.E.M., but where distributions were aggregated, and where data required transformation for analysis, geometric means (GM) are given (Elliott, 1977; Dash, Hall \& Barger, 1988) together with $95 \%$ confidence limits $(95 \%$ $\mathrm{CL})$. These means reflect the abundance of infection as defined by Margolis et al. (1982) and Bush et al. (1997) and include all subjects within the specified group, infected and not infected, for which relevant data were available. The degree of aggregation in the data was calculated by the Index of Discrepancy $(D)$ as described by Poulin (1993) (a value of 0 indicates an even distribution of counts across all hosts and a value of 1 indicates all parasites aggregated in a single host) and the Index of Dispersion ( $I$, variance to mean ratio, where values $>1$ indicate overdispersed data). Frequency distributions of individual species were also tested for goodness of fit to negative binomial, positive binomial and Poisson models by $\chi^{2}$ as described by Elliott (1977) and the negative binomial exponent $k$ is given as appropriate.

Parasite abundance was analysed by GLIM (A statistical system for generalized linear interactive modelling; GLIM 4, PC version, Royal Statistical Society, 1993) as described previously, using models with normal errors after normalization of the data by $\log _{10}(x+1)$ transformation (Crawley, 1993; Wilson \& Grenfell, 1997; Behnke et al. 1999). Site (3 levels, 1, 2 and 3), host age (3 levels) and host sex (2 levels) were entered as factors. We began in all cases with the full factorial models, including all main effects and interactions, and then progressively simplified them by deletion of terms, beginning with the 

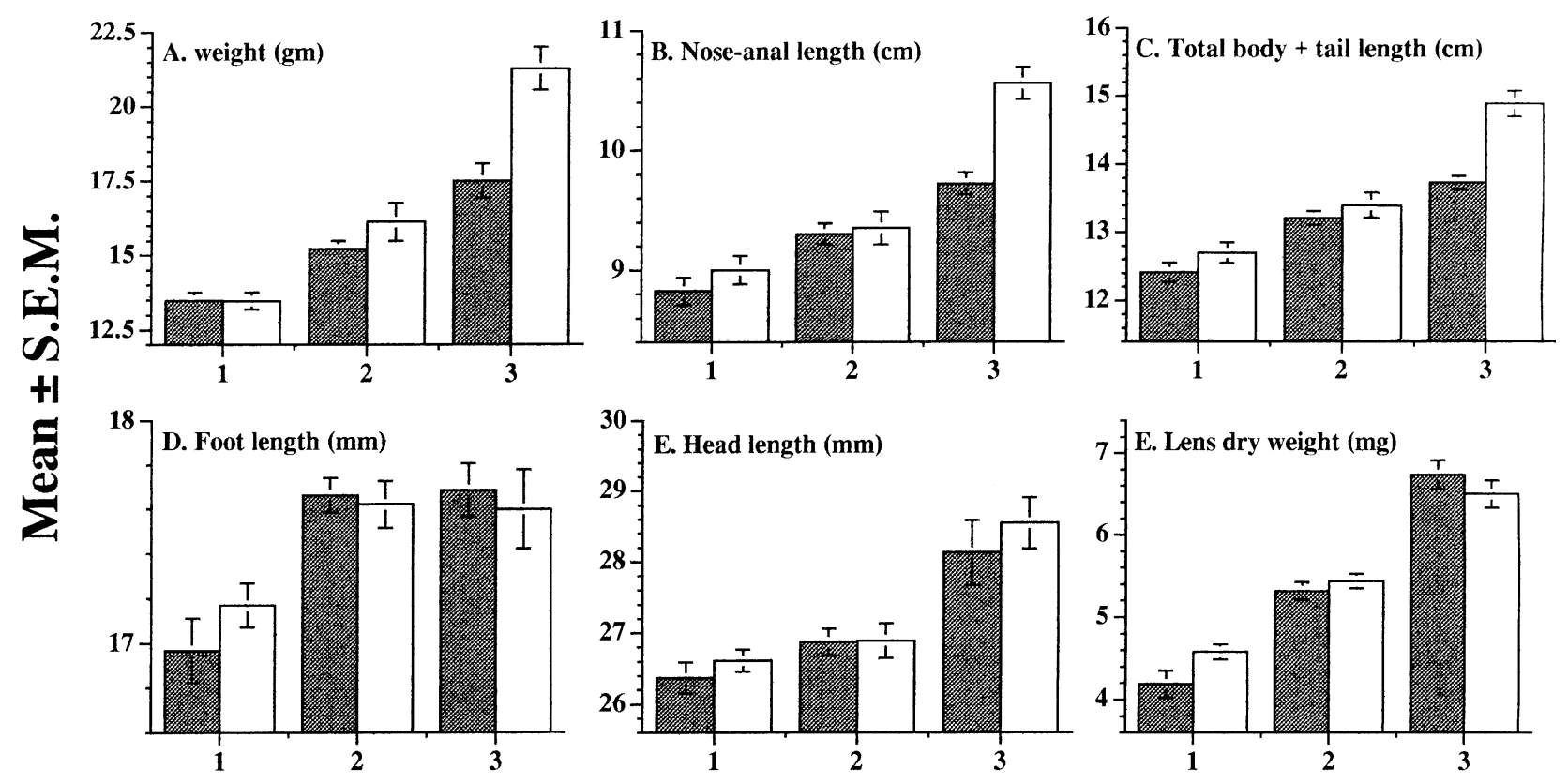

Age class

Fig. 2. Relationship between assigned age-classes and 6 of the morphometric measures used to estimate age (filled in columns $=$ males, open columns $=$ females). (A) Host weight (main effect of age $F_{2,133}=50 \cdot 8, P<0 \cdot 0001$, but there is also a significant effect of $\operatorname{sex} F_{1,133}=17 \cdot 7, P<0 \cdot 0001$, and a significant interaction between sex and age $F_{2,133}=6 \cdot 0$, $P=0 \cdot 003$ ). (B) Nose-anal length (main effect of age $F_{2,133}=42 \cdot 0, P<0 \cdot 0001$, but there is also a significant effect of $\operatorname{sex} F_{1,133}=13 \cdot 8, P=0 \cdot 0003$, and a significant interaction between sex and age $\left.F_{2,133}=5 \cdot 8, P=0 \cdot 004\right)$. (C) Total body and tail length (main effect of age $F_{2,133}=56 \cdot 2, P<0 \cdot 0001$, but there is also a significant effect of sex $F_{1,133}=21 \cdot 3$, $P<0.0001$, and a significant interaction between sex and age $F_{2,133}=6 \cdot 6, P=0 \cdot 002$ ). (D) Average hind foot length (only the main effect of age is significant $F_{2,133}=15 \cdot 8, P<0 \cdot 0001$ ). (E) Skull length (only the main effect of age is significant $F_{2,133}=20 \cdot 7, P<0 \cdot 0001$ ). (F) Dry lens weight (only the main effect of age is significant $F_{2,133}=120 \cdot 6$, $P<0.0001)$.

Table 1. Numbers of Clethrionomys glareolus examined by site, and host sex and age

\begin{tabular}{|c|c|c|c|c|c|c|}
\hline \multirow[b]{2}{*}{ Site } & \multirow[b]{2}{*}{ Sex } & \multicolumn{3}{|c|}{ Age class } & \multirow{2}{*}{$\begin{array}{l}\text { Total } \\
\text { by sex }\end{array}$} & \multirow{2}{*}{$\begin{array}{l}\text { Total } \\
\text { by site }\end{array}$} \\
\hline & & 1 & 2 & 3 & & \\
\hline \multirow[t]{3}{*}{1} & Male & 0 & 15 & 5 & 20 & \\
\hline & Female & 3 & 8 & 9 & 20 & \\
\hline & Combined & 3 & 23 & 14 & & 40 \\
\hline \multirow[t]{3}{*}{2} & Male & 3 & 13 & 4 & 20 & \\
\hline & Female & 8 & 8 & 5 & 21 & \\
\hline & Combined & 11 & 21 & 9 & & 41 \\
\hline \multirow[t]{3}{*}{3} & Male & 13 & 13 & 5 & 31 & \\
\hline & Female & 9 & 13 & 5 & 27 & \\
\hline & Combined & 22 & 26 & 10 & & 58 \\
\hline \multicolumn{7}{|c|}{ Total by sex } \\
\hline & Males & 16 & 41 & 14 & 71 & \\
\hline & Females & 20 & 29 & 19 & 68 & \\
\hline \multicolumn{2}{|c|}{ Total by age } & 36 & 70 & 33 & & \\
\hline
\end{tabular}

highest order interactions, and progressing to the main effects. Two-way interactions were first deleted to register the change in deviance and then reinstated in turn until all 3 had been evaluated. All 2-way interactions were then removed, and the procedure was repeated with the main effects. For models with normal errors the change in deviance is divided by the scale parameter and the result divided by the change in degrees of freedom (D.F.) following each deletion, to give a variance ratio, $F$. Finally, minimum sufficient models were fitted, entering only the significant terms, and the residuals from these were checked for approximately normal distribution.

\section{RESULTS}

\section{Habitat structure}

Comparability of habitat structure at the 3 sites was confirmed quantitatively by analysis of variance (ANOVA) of the percentage scores at the sampling points for the traplines in each of the 3 sites. Scores were aggregated by vegetation level as (a) mean percentage high plus mid-canopy (canopy layer), (b) mean percentage shrub plus tall herbs and tree branch/trunk (shrub layer), and (c) the ratio of percentage ground-layer herbaceous material to percentage bare soil and litter (ground layer). In all 3 cases there was no significant difference between sites (canopy layer $F_{2,27}=2.56$, N.s.; shrub layer $F_{2,27}=2 \cdot 05$, N.s.; ground layer $F_{2,27}=0 \cdot 28$, N.s.). 
Table 2. Prevalence ( $\%$ infected) of helminth taxa by site

\begin{tabular}{|c|c|c|c|c|}
\hline \multirow[b]{2}{*}{ Taxon } & \multirow[b]{2}{*}{ Species } & \multicolumn{3}{|l|}{ Site } \\
\hline & & $1 *$ & $2 *$ & $3 *$ \\
\hline \multirow{6}{*}{ Nematodes } & Heligmosomum mixtum & $95 \cdot 0 \pm 6 \cdot 75$ & $43 \cdot 9+15 \cdot 19$ & 0 \\
\hline & Heligmosomoides glareoli & $7 \cdot 5 \pm 8 \cdot 16$ & $2 \cdot 4 \pm 4 \cdot 72$ & $79 \cdot 3 \pm 10 \cdot 43$ \\
\hline & Syphacia petrusewiczi & $10 \cdot 0 \pm 9 \cdot 30$ & $31 \cdot 7 \pm 14 \cdot 24$ & $3 \cdot 4 \pm 4 \cdot 70$ \\
\hline & Aspiculuris tetraptera & $2 \cdot 5 \pm 4 \cdot 84$ & $12 \cdot 2 \pm 10 \cdot 02$ & $58 \cdot 6 \pm 12.68$ \\
\hline & Mastophorus muris & $10 \cdot 0 \pm 9 \cdot 30$ & 0 & $17 \cdot 2 \pm 9 \cdot 72$ \\
\hline & Trichuris muris & 0 & 0 & $1 \cdot 7 \pm 3 \cdot 35$ \\
\hline All nematodes & & $95 \cdot 0 \pm 6 \cdot 75$ & $68 \cdot 3 \pm 14 \cdot 24$ & $91 \cdot 4 \pm 7 \cdot 22$ \\
\hline \multirow[t]{2}{*}{ Cestodes } & Catenotaenia henttoneni & $20 \cdot 0 \pm 12 \cdot 40$ & $4.9 \pm 6.59$ & $1 \cdot 7 \pm 3 \cdot 35$ \\
\hline & Paranoplocephala gracilis & $2 \cdot 5 \pm 4 \cdot 84$ & 0 & 0 \\
\hline \multirow[t]{4}{*}{ All adult cestodes } & & $22 \cdot 5 \pm 12 \cdot 94$ & $4.9 \pm 6.59$ & $1 \cdot 7 \pm 3 \cdot 35$ \\
\hline & Mesocestoides lineatus & $2 \cdot 5 \pm 4 \cdot 84$ & $2 \cdot 4 \pm 4 \cdot 72$ & $1 \cdot 7 \pm 3 \cdot 35$ \\
\hline & Taenia martis & 0 & 0 & $1 \cdot 7 \pm 3 \cdot 35$ \\
\hline & Taenia mustelae & $2 \cdot 5 \pm 4 \cdot 84$ & 0 & $3 \cdot 4 \pm 4 \cdot 70$ \\
\hline All larval cestodes & & $2 \cdot 5 \pm 4 \cdot 84$ & $2 \cdot 4 \pm 4 \cdot 72$ & $6 \cdot 9 \pm 6 \cdot 52$ \\
\hline All cestodes & & $25 \cdot 0 \pm 13 \cdot 42$ & $7 \cdot 3 \pm 7 \cdot 97$ & $8 \cdot 6 \pm 7 \cdot 22$ \\
\hline \multicolumn{2}{|c|}{ All helminths (nematodes and cestodes combined) } & $95 \cdot 0 \pm 6 \cdot 75$ & $68 \cdot 3 \pm 14 \cdot 24$ & $91 \cdot 4 \pm 7 \cdot 22$ \\
\hline
\end{tabular}

* Prevalence $(\%$ infected $) \pm 95 \%$ confidence limits.

Table 3. Measures of component community structure by site

\begin{tabular}{llll}
\hline \hline & Site & \\
\cline { 2 - 4 } & 1 & 2 & 3 \\
\hline $\begin{array}{l}\text { Total no. of helminth } \\
\text { species identified }\end{array}$ & 9 & 6 & 9 \\
$\begin{array}{l}\text { Berger-Parker } \\
\text { dominance index }\end{array}$ & 0.934 & 0.909 & 0.684 \\
$\begin{array}{l}\text { Dominant species } \\
\text { Simpson's index }\end{array}$ & $\begin{array}{l}\text { S. petrusewiczi } \\
0.125\end{array}$ & $\begin{array}{l}\text { S. petrusewiczi } \\
0 \cdot 167\end{array}$ & $\begin{array}{l}\text { A. tetraptera } \\
0.457\end{array}$ \\
\hline \hline
\end{tabular}

Clethrionomys glareolus

A total of 139 bank voles was sampled from the 3 study sites. The structure of the host population by site, host sex and age is summarized in Table 1. Although samples from the 3 sites did not differ significantly in respect of the relative numbers of the two sexes, there was a significant difference in the numbers of voles among the 3 age classes $\left(\chi^{2}=13 \cdot 9\right.$, D.F. $=4, P=0.0075)$. Voles in age class 2 formed the largest proportion of the sampled animals from all 3 sites $(57.5,51.2$ and $44.8 \%$ for sites 1,2 and 3 respectively). However, voles from the youngest age class comprised a larger proportion of the sample from site 3 and were least well represented in site 1 $(7 \cdot 5,26 \cdot 8$ and $36 \cdot 9 \%$ for sites 1,2 and 3 respectively).

Measures of component community structure

Total species richness and component species. Eleven species of helminths were recorded in total, 6 nematodes and 5 cestodes (Table 2) and 119 voles $(85.6 \%)$ carried at least 1 of these species. The 2 heligmosomid species, H. mixtum and $H$. glareoli, were the most prevalent helminths among all the voles combined $(40.3 \%$ and $36.0 \%$ respectively), but there were marked differences in their prevalence, as well as that of other helminths, between sites.

Total species richness, dominant species and diversity indices by site. The number of helminth species recorded at sites 1 and 3 were higher than at site 2 (Table 3). However, sites 1 and 2 had the highest Berger-Parker dominance indices and the lowest Simpson's diversity indices, because of the very high worm burdens with $S$. petrusewiczi in a small proportion of voles from these sites (Table 4). In site 3 the dominant species at the component community level was $A$. tetraptera.

Measures of infracommunity structure

Mean species richness. The overall mean number of species harboured per host (all voles combined) was 
$1 \cdot 44 \pm 0.076$ (variance to mean ratio $=0.55$ ). Mean species richness was marginally higher at site 3 compared with site 1 , but relatively low at site 2 (Table 5; 3-way ANOVA in GLIM with normal errors and site, host age and sex as factors, main effect of site $F_{2,135}=9 \cdot 134, P<0.001$ ). There was also a significant main effect of host age (Fig. 3A, $\left.F_{2,135}=4 \cdot 611, P=0.01\right)$ with mean species richness increasing from the youngest voles (age class 1) through to the oldest (age class 3) but no effect of host sex (mean species richness in males $=1.45 \pm$ $0 \cdot 109$, females $=1 \cdot 43 \pm 0 \cdot 107)$. There were no significant interactions.

Measures of infracommunity diversity. The maximum number of helminth species per vole ranged from 2 in site 2 to 4 in site 3 . The mean number of helminths harboured per vole appeared to differ with sites 1 and 2 showing considerably higher mean values than site 3 , principally because of the few animals from the former sites carrying very heavy $S$. petrusewiczi burdens. However, statistical analysis (3-way ANOVA in GLIM with site, sex and age as factors on $\log _{10}(x+1)$ transformed data) revealed only a significant 3 -way interaction $\left(F_{3,125}=3 \cdot 212\right.$, $0 \cdot 025>P>0 \cdot 01$ ).

There was a significant difference in the value of Brillouin's diversity index across the 3 sites (Table 5; 3-way ANOVA in GLIM with site, sex and age as factors, $\left.F_{2,135}=10.431, P<0.001\right)$, the highest mean value being generated by voles from site 3 and the lowest by those from site 1 . There were no other significant terms in this analysis but the main effect of age was only just outside significance $\left(F_{2,135}=\right.$ $2 \cdot 383,0 \cdot 1>P>0 \cdot 05)$, and the mean values show an increase in diversity with increasing age (Fig. 3B).

Species density distributions. The species density distributions at each site are shown in Fig. 4. As can be seen the majority of animals harboured 1 or 2 species. At sites 1 and 3 some animals harboured 3 species but only 1 vole, from site 3 , harboured the maximum number of 4 species. These distributions were adequately described by both positive and negative binomial models but only that for site 2 was compatible with the Poisson distribution. The data from each site were combined (Fig. 4D) and compared to the distribution predicted by the null model for interactions of parasite species in an assemblage (Janovy et al. 1995). No significant difference was found $\left(\chi^{2}=2 \cdot 9\right.$, D.F. $\left.=4, P>0.05\right)$.

Prevalence of species and higher taxa. The prevalence data are summarized by site in Table 2 . At the highest taxonomic level (all helminths combined), voles from site 2 had lower prevalence of helminths than those from sites 1 and 3 . The minimum sufficient model (analysis by log linear maximum 
Table 5. Measures of infracommunity structure by site

\begin{tabular}{lccc}
\hline \hline & \multicolumn{3}{l}{ Site } \\
\cline { 2 - 4 } & 1 & 2 & 3 \\
\hline Mean number of species \pm s.E.M. & $1 \cdot 53 \pm 0 \cdot 13$ & $0 \cdot 98 \pm 0 \cdot 12$ & $1 \cdot 71 \pm 0 \cdot 12$ \\
Maximum number of species & 3 & 2 & 4 \\
Mean no. of helminths \pm s.E.M. & $109 \cdot 9 \pm 100 \cdot 5$ & $126 \cdot 9 \pm 72 \cdot 0$ & $16 \cdot 1 \pm 4 \cdot 0$ \\
Mean Brillouin's index \pm s.E.M. & $0 \cdot 135 \pm 0 \cdot 034$ & $0 \cdot 167 \pm 0 \cdot 027$ & $0 \cdot 209 \pm 0 \cdot 040$ \\
Maximum Brillouin's index & $0 \cdot 653$ & $0 \cdot 461$ & $0 \cdot 968$ \\
\hline \hline
\end{tabular}

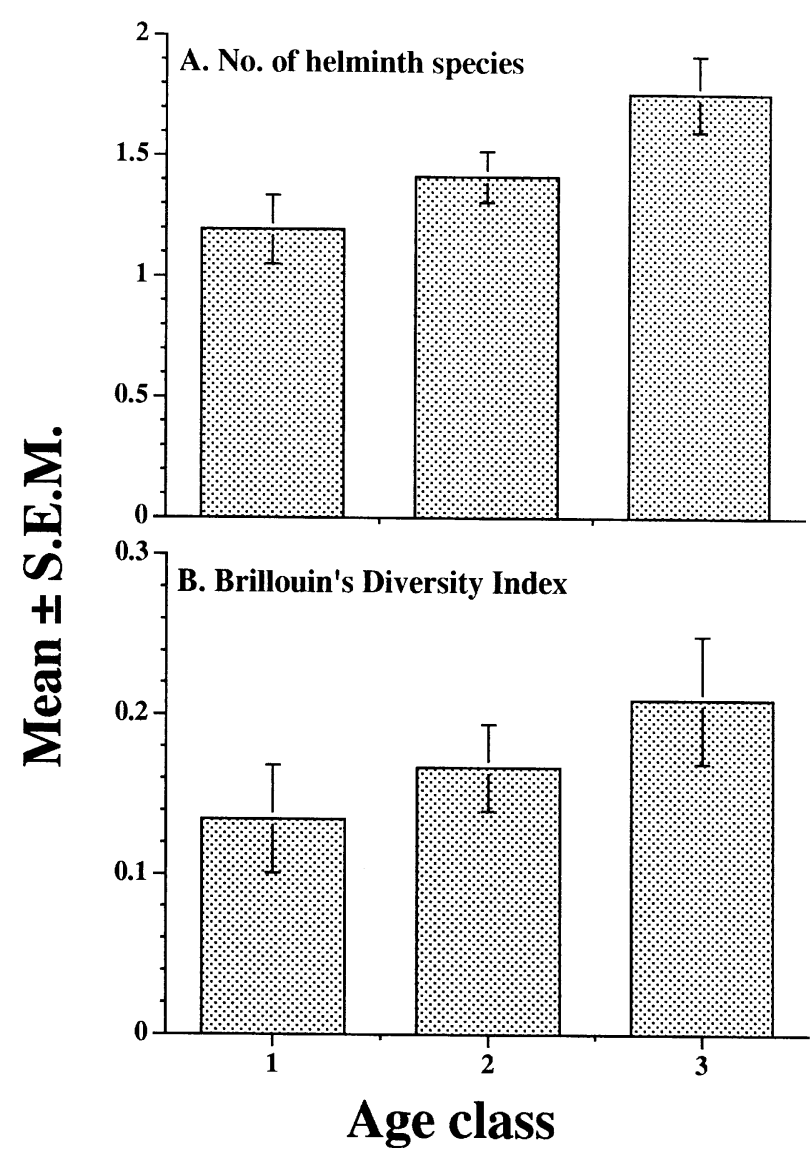

Fig. 3. Age-dependent variation in mean species richness (A) and Brillouin's Diversity Index (B). For statistical analysis see text.

likelihood) included only 2 terms, site $\times$ age and site $\times$ infection $\left(\chi^{2}=26 \cdot 6,24\right.$ D.F., $\left.P=0 \cdot 323\right)$, indicating that the number of animals in respective age classes and prevalence of infection with helminths varied between sites. An identical picture emerged for nematodes, since all cestodes were encountered only in animals that also carried nematodes and no other higher helminth taxa were recorded in this study.

The prevalence of $H$. mixtum varied considerably between sites (minimum sufficient model $=$ site $\times$ infection and site $\times$ age, $\chi^{2}=28 \cdot 0$, D.F. $=24, P=$ $0 \cdot 260$ ) with the majority of voles in site 1 carrying this species, compared with none of the 58 voles sampled from site 3 (Table 2).
Prevalence of infection with $H$. glareoli showed an opposite pattern with $79.3 \%$ of voles from site 3 infected, and only $7.5 \%$ at site 1 . The minimum sufficient model for this species was more complex than that for $H$. mixtum $\left(\chi^{2}=11 \cdot 4\right.$, D.F. $=16, P=$ $0 \cdot 783$ ). The site $\times$ age interaction term was expected but there were also 2 additional terms: a significant effect of site on infection (Table 2) but also an independent effect of sex and age on infection (Fig. $5)$. The oldest animals showed the lowest prevalence with this species, but whereas in males peak prevalence was in the youngest animals, among females it was in age class 2 .

Prevalence of infection with the 2 oxyuroids varied only in relation to site, but in different combinations. Voles from site 2 had the highest prevalence of $S$. petrusewiczi (the minimum sufficient model incorporated interaction terms: site $\times$ age and site $\times$ infection; $\chi^{2}=27 \cdot 6$, D.F. $=24, P=0 \cdot 277$ ) whereas those from site 3 the lowest (Table 2). However, $A$. tetraptera showed the highest prevalence in site 3 and the lowest in site 1 (similar model but $\chi^{2}=26 \cdot 1$, D.F. $=24, P=0.348$ ).

$M$. muris was encountered too infrequently to permit analysis of prevalence but Table 2 shows that this species was only recovered from sites 1 and 3 . A single specimen of T. muris was recovered from a female vole from site 3 .

None of the cestodes showed prevalence in excess of $10 \%$. Among adult cestodes, C. henttoneni was the most common, 8 of the 11 animals harbouring this species originating from site 1 . In addition Paranoplocephala gracilis was only found at site 1, and consequently when the prevalence of adult cestodes (all species pooled) was analysed, the minimum sufficient model confirmed that a site $\times$ infection term was essential $\left(\chi^{2}=22 \cdot 2\right.$, D.F. $\left.=24, P=0.567\right)$.

Larval cestodes were rarer still and hence no further analysis was undertaken. Three animals (1 from each site) harboured $M$. lineatus, the single specimen of T. martis came from site 3 , and 2 of the $3 T$. mustelae were from site 3 with the remaining worm being from a vole from site 1 .

Frequency distributions and measures of aggregation. The frequency distributions of all species for which quantitative analysis was possible were examined 

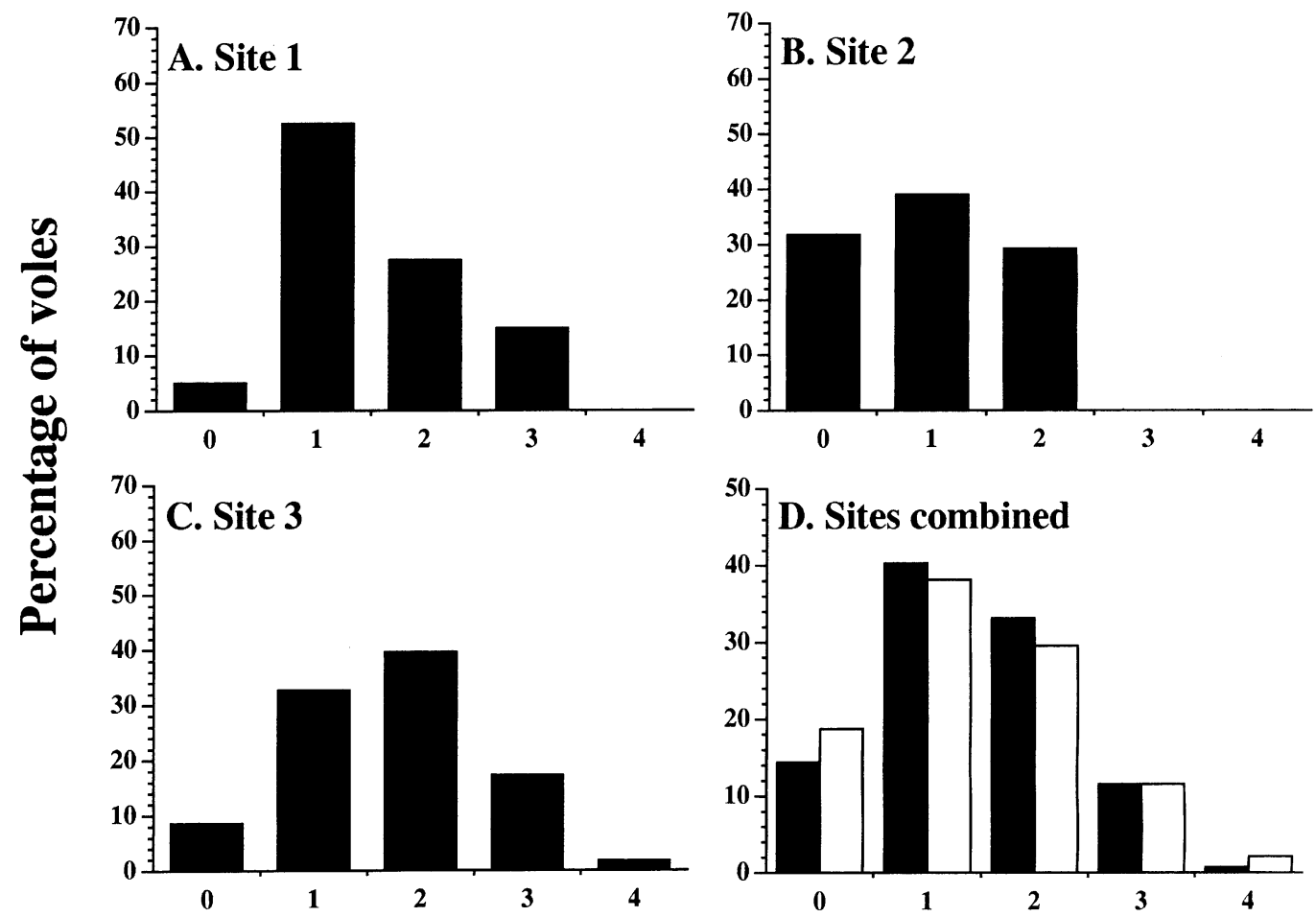

No. of helminth species harboured

Fig. 4. Frequency distribution of infracommunity species richness for site 1 (A), site 2 (B), site 3 (C) and combined (D). In (D) the observed combined data is in the filled in columns and that predicted by the null model of Janovy et al. (1995) in the open columns. See text for full explanation and statistical analysis.

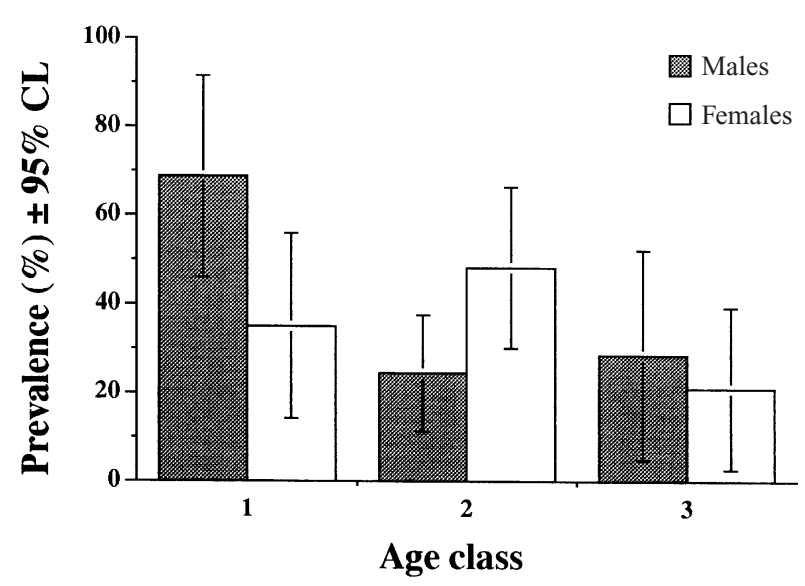

Fig. 5. Age and site-specific differences in prevalence of Heligmosomoides glareoli (filled in columns = male; open columns $=$ females).

and the summary statistics are given in Table 6 . It was not possible to test all for significance because of insufficient degrees of freedom arising from too few animals carrying infection in some cases, particularly in low worm burden classes. Among those which could be tested, none were compatible with positive binomial or Poisson distributions. In site $1, H$. mixtum and $S$. petrusewiczi could not be tested for goodness of fit to the negative binomial but the values of $I$ indicated overdispersion, and both distributions differed significantly from those expected of the positive binomial and Poisson distribu- tions. In site 2 the distributions of H. mixtum and $S$. petrusewiczi were well described by the negative binomial, and the values of $D$ suggested that $H$. glareoli and A. tetraptera were also aggregated. In site $3 \mathrm{H}$. glareoli and $\mathrm{A}$. tetraptera conformed to the negative binomial and the value of $D$ suggested also that $S$. petrusewiczi was aggregated.

Abundance of infection. Analysis of H. mixtum by 3way ANOVA in GLIM (after normalization by $\log _{10}$ $[x+1]$ transformation) revealed that there was a highly significant main effect of site $\left(\mathrm{F}_{2,135}=43 \cdot 0\right.$, $P<0.001)$, but also a significant interaction between site and sex $\left(F_{2,127}=5 \cdot 88, P<0 \cdot 005\right)$. As Fig. 6A shows, abundance was highest in voles from site 1 , but higher in females compared with males. In site 2 males carried marginally higher infections than females and in site 3 none of the voles were infected with $H$. mixtum.

For $H$. glareoli statistical analysis of $\log _{10}(x+1)$ normalized data by 3 -way ANOVA showed that only the main effect of site was significant $\left(\mathrm{F}_{2,135}=36 \cdot 61\right.$, $P<0.001$ ), and that no other main effects (sex and age) nor interactions contributed to the minimum sufficient model. Clearly site 3 had voles with the highest mean abundance of worms and sites 1 and 2 were much lower (Fig. 6B). However, we suspected an underlying age effect and in a post-hoc analysis, confined to site 3 since the majority of animals carrying this species were from this site, confirmed 
Table 6. Measures of aggregation for individual species of nematodes by site

\begin{tabular}{|c|c|c|c|c|c|c|c|c|c|}
\hline \multirow[b]{2}{*}{ Species } & \multicolumn{3}{|l|}{ Site 1} & \multicolumn{3}{|l|}{ Site 2} & \multicolumn{3}{|l|}{ Site 3} \\
\hline & $\begin{array}{l}k^{*} \\
( \pm \text { s.E.M.§) }\end{array}$ & $\mathrm{I} \uparrow$ & $D \ddagger$ & $\begin{array}{l}k^{*} \\
( \pm \text { s.E.M.§) }\end{array}$ & $I \dagger$ & $D \ddagger$ & $\begin{array}{l}k^{*} \\
( \pm \text { s.E.M.§) }\end{array}$ & $I \dagger$ & $D \ddagger$ \\
\hline Heligmosomum mixtum & $\begin{array}{l}3.5329, \| \\
(1.502)\end{array}$ & $2 \cdot 434$ & $0 \cdot 357$ & $\begin{array}{l}0 \cdot 520 \#, \| \\
(0 \cdot 224)\end{array}$ & $2 \cdot 564$ & $0 \cdot 671$ & N.D. & N.D. & N.D. \\
\hline Heligmosomoides glareoli & N.D. & $0 \cdot 949$ & $0 \cdot 902$ & N.D. & $1 \cdot 00$ & $0 \cdot 952$ & $\begin{array}{l}1 \cdot 204 \#, \| \\
(0 \cdot 324)\end{array}$ & $3 \cdot 620$ & $0 \cdot 480$ \\
\hline Syphacia petruseziczi & $\begin{array}{l}0 \cdot 0189, \| \\
(0 \cdot 007)\end{array}$ & 3945 & $0 \cdot 933$ & $\begin{array}{l}0 \cdot 067 \#, * * * \\
(0 \cdot 019)\end{array}$ & 1847 & $0 \cdot 834$ & $\begin{array}{l}0 \cdot 0299, * * * \\
(0 \cdot 023)\end{array}$ & $2 \cdot 474$ & 0.958 \\
\hline Aspiculuris tetraptera & N.D. & 1 & $0 \cdot 951$ & $\begin{array}{l}0.023 \mathbf{g}, \| \\
(0 \cdot 009)\end{array}$ & $184 \cdot 3$ & $0 \cdot 930$ & $\begin{array}{l}0 \cdot 216 \#, \| \\
(0 \cdot 044)\end{array}$ & $81 \cdot 84$ & $0 \cdot 800$ \\
\hline
\end{tabular}

* Negative binomial exponent.

$\uparrow$ Index of dispersion = variance to mean ratio.

† Index of discrepancy (Poulin, 1993).

$\S$ Standard error of the mean estimate.

I Not possible to test for goodness of fit to negative binomial distribution.

\# Not significantly different from negative binomial distribution.

$\|$ Significantly different from positive binomial and Poisson distributions.

** Not possible to test for goodness of fit to positive binomial and Poisson distributions.

N.D., Not possible to calculate statistic.
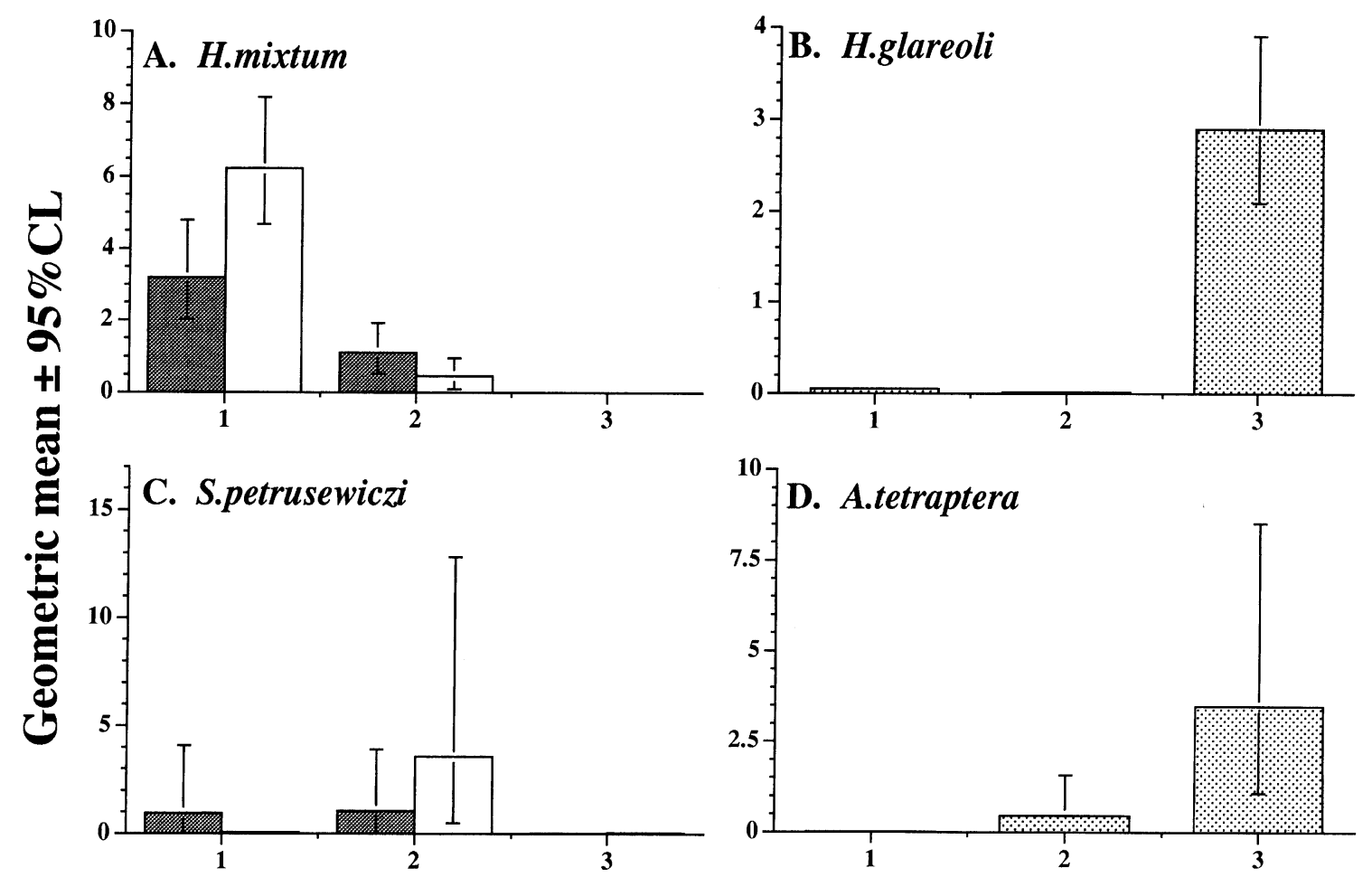

Site

Fig. 6. Quantitative differences in parasite burdens between the 3 sites (filled in columns $=$ male, open columns $=$ females). (A) Heligmosomum mixtum. (B) Heligmosomoides glareoli. (C) Syphacia petrusewiczi. (D) Aspiculuris tetraptera. For statistical analysis see text.

that there was indeed no significant effect of age (main effect of age, $F_{2,56}=1 \cdot 23, P=$ N.s.), even though the geometric mean values fell from 3.82 (95\% CL 2.30-6.04), through $2 \cdot 60 \quad(95 \%$ CL $1 \cdot 54-4 \cdot 10)$ to $2 \cdot 0(95 \%$ CL $0 \cdot 52-4 \cdot 91)$ in age classes $1-3$ respectively.
In both oxyuroid species, following analysis of $\log (x+1)$ transformed data, the only significant main effect was that of site ( $S$. petrusewiczi, $F_{2,135}=43 \cdot 0$, $P<0.001 ; A$. tetraptera, $\left.F_{2,135}=12 \cdot 38, P<0.001\right)$. However, in the case of $S$. petrusewiczi there was a significant 2-way interaction between site and sex 
$\left(F_{2,127}=5.98, P<0.005\right)$ and this is illustrated in Fig. $6 \mathrm{C}$ where it can be seen that voles from site 3 had very low mean abundance and those from site 2 the highest, but this was confounded by a sex difference with a higher mean abundance in female voles. In site $1 S$. petrusewiczi showed an intermediate abundance but was higher in male compared with female voles. In contrast to $S$. petrusewiczi, voles from site 3 had the highest mean abundance of A. tetraptera (Fig. 6D). However, this was complicated by a 3 -way interaction with sex and age $\left(F_{3,125}=3.46,0.025>P>0.01\right)$.

None of the remaining parasites were present in sufficient animals to merit analysis.

\section{ISCUSS I O N}

The data presented in this paper clearly show that differences in the helminth communities harboured by bank voles from the 3 study sites existed at both component and infracommunity levels. Although 11 species of helminths were identified in total, the species list did not exceed 9 for any of the 3 sites. At the component community level, voles from site 2 had fewer species of helminths but it was site 3 that differed with respect to dominance and diversity indices. These indices were very similar at sites 1 and 2 (high for the Berger-Parker dominance index, and low for the Simpson's index) and were primarily generated through the voles that were very heavily infected with $S$. petrusewiczi. Nematodes of the genus Syphacia can accumulate to a high abundance through autoinfection, facilitated by eggs that are infective within hours of being released by female worms onto the perianal surface of the host (Lewis, 1968). At site 3 A. tetraptera was the dominant species, representing $68.4 \%$ of all recovered helminths, but, as with $S$. petruserwiczi, this nematode was not the most prevalent at the site.

Differences between the sites were also evident at the infracommunity levels in respect of mean species richness, mean Brillouin's index and in the prevalence and quantitative worm burdens of particular species. The lowest mean species richness, lowest prevalence of both nematodes and cestodes was recorded for voles from site 2 and none of the 6 species of helminths from this site infected more than $43.9 \%$ of the voles. In fact the prevalence of the most common species, the heligmosomids combined, did not exceed $50 \%$ in voles from this site. However, voles from site 2 showed the highest prevalence of $S$. petrusewiczi with 5 animals harbouring in excess of 100 worms. It was these few heavily infected animals that generated the high value for the mean number of helminths/vole from this site. In contrast, voles from sites 1 and 3 both had a higher but similar mean species richness but in each site a different species of nematode showed the highest prevalence. In site 1 it was $H$. mixtum that infected $95 \%$ of the animals and in site $3 \mathrm{H}$. glareoli showed the highest prevalence, with $79.3 \%$ of the voles carrying this species. Each of these 2 closely related nematodes can be regarded as a core species in its respective site. Other species were rare in site 1 (although the prevalence of adult tapeworms was the highest) whereas site 3 was also characterized by the highest prevalence with $A$. tetraptera and $M$. muris. When the quantitative data were analysed at higher taxonomic levels, no clear distinctions were found between the sites, because the individual species compensated for lack of others.

As expected from other studies of helminths in wood mice and voles, there was no evidence in our data for sex bias in infections (Kisielewska, 1970c; O'Sullivan et al. 1984; Abu-Madi et al. 2000). Agerelated differences in parasite burdens are more difficult to assess because of the problem of accurate ageing (Morris, 1972). Most workers have employed host weight to estimate age but, at best, this can be regarded as only an approximate indicator since older animals can lose condition for a variety of reasons, not the least from heavy parasite infections and seasonal changes in availability of food. A more reliable indicator is the dry weight of lenses, but few studies have exploited this as an indicator of age or combined lens weight with other morphometric measurements. However, we paid special attention to age estimation, using eye lens weight and a range of other morphometric measurements to allocate voles to 3 age classes. Hence it was surprising to find that there were few age effects in our data. Interestingly mean species richness increased significantly from age class 1 through to class 3 , and the mean Brillouin's index showed a corresponding increase although it was just outside significance. Both trends are consistent with the idea that older animals will have had a longer opportunity to acquire infections and that most of the helminth parasites are relatively long-lived in relation to the natural life-span of the host. At the individual species level, the only significant age-related effect was on the prevalence of H. glareoli. The oldest age-class showed the lowest prevalence which, although intuitively unexpected, might indicate that animals acquire resistance with duration of exposure. Gregory (1992) also identified a trend of decreasing worm burdens among the heaviest wood mice (Apodemus sylvaticus) infected with Heligmosomoides polygyrus. Thus the peak prevalence of infection in females in age class 2 is consistent with this idea, but perhaps surprisingly it was the youngest males that showed the highest prevalence. Analysis of the quantitative data did not confirm a significant effect of age, even when confined to voles from site 3 , but a trend of falling worm counts from the youngest to the oldest voles was evident.

Our study adds to those of Kisielewska et al. (1973), Krasowska (1974), Montgomery \& Montgomery (1990) and to the recent study by Haukisalmi 
\& Henttonen (1999) which have drawn attention to spatial heterogeneity, at both local and regional levels, as a factor in shaping the helminth component communities in wild rodents. Montgomery \& Montgomery (1990) studied a range of sites which encompassed deciduous, coniferous and grassland sites in Northern Ireland and concluded that neither proximity nor the gross habitat characteristics were key determinants of helminth communities. Moreover, some helminth communities of Apodemus sylvaticus changed quite radically whilst others remained unchanged over a 5 year period. Abu-Madi et al. (2000) studied 3 sites which differed quite markedly in their habitat structure, and associated high worm burdens and mean species richness with mice from semi-isolated populations living in hedgerows on agricultural land. Haukisalmi \& Henttonen (1999) concluded that aggregation of helminth parasites was primarily determined within sites rather than between them, and hence local factors played a key role in promoting dissimilarity between sites (see also Hartvigsen \& Kennedy, 1993).

In our study, voles from 3 woodland habitats, which were selected because of their gross similarity to each other in respect of habitat quality, were shown to carry quite different combinations and intensities of infection. Our study sites were sufficiently distant from one another to exclude the possibility that voles interchanged between them regularly, and each was surrounded by a combination of open ground and water, making them essentially island habitats (Gerlach \& Musolf, 2000). Our data add weight to the idea that spatial factors contribute significantly to shaping helminth component communities in rodents even at a local level $(<30 \mathrm{~km})$ but the principal conclusion from our study is that even sites intentionally selected on the basis of the similarity of their habitat quality may differ substantially in this respect.

The question then arises as to why this should be the case. If the voles are indeed isolated in each of our 3 study sites (allopatric host-parasite combination), then genetic differences may play a role (Lively \& Dybdahl, 2000; Gerlach \& Musolf, 2000). In this context it is relevant that we were able to detect significant phenotypic variation between the vole populations from the 3 sites, as reflected in differences in morphometric measurements, including body size and limbs (after controlling for age and sex; Barnard et al. manuscript in preparation). Moreover, recent studies have shown that rivers and even highways can act as isolating mechanisms for $C$. glareolus, with detectable differences at the genetic level between populations separated by such barriers (Gerlach \& Musolf, 2000). It is equally possible that local variation in host population structure combined with subtle differences in life-history strategies as reflected in behaviour, reproduction and investment in immune function, may generate sufficient dif- ferences between the populations to affect risk of exposure, susceptibility and resistance to infection (sympatric host-parasite combination).

On the other hand, attention has been drawn to the stochastic nature of the processes that govern helminth communities in other animals, for example fish (Hartvigsen \& Kennedy, 1993). Thus local factors have been suggested to play an important role in promoting dissimilarity in helminth community structure in brown trout from reservoirs of comparable habitat quality. Similarly, differences between our sites may have been based to some extent on chance, and the likelihood that transmission stages of some parasites became extinct (extinction events) or were introduced to the local vole population (colonization events) either by migrating or dispersing voles (helminths with direct cycles) or prey/predators (helminths with indirect cycles). With respect to cestodes, which only accounted for $1.5 \%$ of all the helminths recovered (total $=10530$ individual worms), the availability of insect intermediate and mammalian definitive hosts may have been a factor. However, all the 6 nematode species have direct life-cycles, 3 are specific to bank voles, 2 (A. tetraptera and T. muris) are specific to rodents and only $M$. muris may have a wider range of hosts. At this stage, there are no indications as to the identity of the factors responsible for the contrasting helminth component communities in rodents from our 3 sites. However, their identification, and that of the processes involved, are the long-term goals in our project.

We are grateful to the University of Nottingham for the provision of travel expenses and to British Council, UK and the State Committee for Scientific Research (KBN), Poland for financial support for this study (KBN Grants UM 855 and UM 930). We thank Professor M. Kozakiewicz and Dr R. Halba for use of the field station at Urwitalt (Dept. of Ecology, Institute of Zoology) and Dr A. Kowalczewski for use of the field station at Pilchy (Dept. of Hydrobiology, Institute of Zoology). We thank Simon Clifford for assistance with the preparation of the local map of Poland. Finally we wish to acknowledge the support of the forestry departments responsible for the woodland sites utilized in our study (Nadleśnictwa Giżycko, Mikołajki and Orzysz).

\section{REFERENCES}

ABU-MADi, M. A., BEHNKE, J. M., LEWIS, J. W. \& GILBERT, F. S. (2000). Seasonal and site specific variation in the component community structure of intestinal helminths in Apodemus sylvaticus from three contrasting habitats in south-east England. Fournal of Helminthology 74, 7-16.

ALIBHAI, S. K. \& GIPPS, J. H. W. (1985). The population dynamics of bank voles. In The Ecology of Woodland Rodents Bank Voles, and Wood Mice (ed. Flowerdew, J. R., Gurnell, J. \& Gipps, J. H. W.), Symposia of the Zoological Society of London 55, pp. 277-313.

Clarendon Press, Oxford. 
BARNARD, C. J. \& BEHNKE, J. M. (2001). From psychoneuroimmunology to ecological immunology: life history strategies and immunity trade-offs. In Psychoneuroimmunology (ed. Ader, R., Felten, D. L. \& Cohen, N.), 3rd Edn, Vol. 2, pp. 35-47. Academic Press, San Diego.

BEHNKE, J. M., LEWIS, J. W., MOHD ZAIN, S. N. \& GILBERT, F. s. (1999). Helminth infections in Apodemus sylvaticus in southern England: interactive effects of host-age, sex and year on prevalence and abundance of infections. Fournal of Helminthology 73, 31-44.

BUSh, A. O., LAFFERTy, K. D., LOTZ, J. M. \& Shostak, A. W. (1997). Parasitology meets ecology on its own terms: Margolis et al. revisited. Fournal of Parasitology 83, 575-583.

CRAWLEY, M. T. (1993). GLIM for Ecologists. Blackwell Scientific Press, Oxford.

DASH, K. M., HALL, E. \& BARGER, I. A. (1988). The role of arithmetic and geometric mean worm egg counts in faecal egg count reduction tests and in monitoring strategic drenching programs in sheep. Australian Veterinary Fournal 65, 66-68.

ELliott, J. M. (1977). Some Methods for the Statistical Analysis of Samples of Benthic Invertebrates. Freshwater Biological Association, Cumbria, UK. GENOV, T. \& YANCHEv, Y. (1981). Morphology and taxonomy of the nematodes of the genera Heligmosomoides Hall, 1916 and Heligmosomum Railliet et Henry, 1909 (Heligmosomidae Cram, 1927) from Bulgaria. Khelmintologiya 12, 8-30.

GERLACH, G. \& MUSOLF, K. (2000). Fragmentation of landscape as a cause for genetic subdivision in bank voles. Conservation Biology 14, 1066-1074.

GREGORY, R. D. (1992). On the interpretation of hostparasite ecology: Heligmosomoides polygyrus (Nematoda) in wild wood mouse (Apodemus sylvaticus) populations. Fournal of Zoology, London 226, 109-121.

HANSKI, I. A. (1997). Metapopulation dynamics: from concepts to predictive models. In Metapopulation Biology : Ecology, Genetics and Evolution (ed. Hanski, I. A. \& Gilpin, M. E.), pp. 69-91. Academic Press, San Diego.

Hartvigsen, R. \& Kennedy, C. R. (1993). Patterns in the composition and richness of helminth communities in brown trout, Salmo trutta, in a group of reservoirs. Fournal of Fish Biology 43, 603-615.

HaUkisalmi, v. \& HeNtTonen, H. (1999). Determinants of helminth aggregation in natural host populations: individual differences or spatial heterogeneity? Ecography 20, 629-636.

haukisalmi, v., henttonen, H. \& Tenora, F. (1988). Population dynamics of common and rare helminths in cyclic vole populations. Fournal of Animal Ecology 57, 807-825.

Haukisalmi, v. \& Tenora, F. (1993). Catenotaenia henttoneni sp.n. (Cestoda: Catenotaeniidae), a parasite of voles Clethrionomys glareolus and C. rutilus (Rodentia). Folia Parasitologica 40, 29-33.

hillgarth, N. \& Wingfield, J. C. (1997). Testosterone and immunosuppression in vertebrates: implications for parasite-mediated anal sexual selection. In Parasites and Pathogens : Effects on Host Hormones and Behaviour (ed. Beckage, N. E.), pp. 143-155. Chapman and Hall, London.
HUDSON, P. J. \& DOBSON, A. P. (1997). Host-parasite processes and demographic consequences. In Host-Parasite Evolution: General Principles and Avian Models (ed. Clayton, D. \& Moore, J.), pp. 128-155. Oxford University Press, Oxford.

JANOVY, J. JR., CLOPTON, R. E., CLOPTON, D. A., SNYDER, S. D., EFTING, A. \& KREBS, L. (1995). Species density distributions as null models for ecologically significant interactions of parasite species in an assemblage. Ecological Modelling 77, 189-196.

KENNEDY, C. R. \& HARTVIGSEN, R. A. (2000). Richness and diversity of intestinal metazoan communities in brown trout Salmo trutta compared to those of eels Anguilla anguilla in their European heartlands. Parasitology 121, 55-64.

KENNEDy, C. R., HARTVigSEN, R. \& HALVORSEN, O. (1991). The importance of fish stocking in the dissemination of parasites throughout a group of reservoirs. Fournal of Fish Biology 38, 541-552.

KISIELEWSKA, K. $(1970 a)$. Ecological organization of intestinal helminth groupings in Clethrionomys glareolus (Schreb.) (Rodentia). 1. Structure and seasonal dynamics of helminth groupings in a host population in the Białowieza National Park. Acta Parasitologica Polonica 18, 121-147.

KISIELEWSKa, K. (1970b). Ecological organization of intestinal helminth groupings in Clethrionomys glareolus (Schreb.) (Rodentia). III. Structure of the helminth groupings in C. glareolus populations of various forest biocoenoses in Poland. Acta Parasitologica Polonica 18, 163-176.

KISIELEWSKA, к. $(1970 c)$. Ecological organization of intestinal helminth groupings in Clethrionomys glareolus (Schreb.) (Rodentia). IV. Spatial structure of a helminth grouping within the host population. Acta Parasitologica Polonica 18, 177-196.

KISIELEWSKa, K., FRACZAK, K., KRASOWSKa, I. \& zubCZEWSKa, z. (1973). Structure of the intestinal helminthocoenosis in the population of Microtus arvalis Pallas, 1778, and the mechanisms of its variability. Acta Parasitologica Polonica 21, 71-83.

KOZAKIEWICZ, M. (1976a). Migratory tendencies in population of bank voles and description of migrants. Acta Theriologica 21, 321-338.

Kozakiewicz, M. (1976b). The weight of eye lens as the proposed age indicator of the bank vole. Acta Theriologica 21, 314-316.

Krasowska, I. (1974). Studies on the dynamics and spatial structure of helminthocoenosis in an isolated population of Microtus arvalis (Pallas, 1778). Wiadomości Parazytologiczne 20, 739-742.

LANGLEY, R. \& FAIRLEY, J. S. (1982). Seasonal variations in infestations of parasites in a wood mouse Apodemus sylvaticus population in the west of Ireland. Fournal of Zoology, London 198, 249-261.

LEWIS, J. W. (1968). Studies on the helminth parasites of the long-tailed field mouse, Apodemus sylvaticus sylvaticus from Wales. Fournal of Zoology, London 154, 287-312.

Lively, C. M. \& DYBDAhl, M. F. (2000). Parasite adaptation to locally common host genotypes. Nature, London 405, 679-681.

MARGOlis, L., ESCH, G. W., HOLMES, J. C., KURIS, A. M. \& SCHAD, G. A. (1992). The use of ecological terms in 
parasitology (report of an ad hoc committee of The American Society of Parasitologists). Fournal of Parasitology 68, 131-133.

MONTGOMery, s. S. J. \& MONTGOMERY, W. I. (1990). Structure, stability and species interactions in helminth communities of wood mice Apodemus sylvaticus. International Fournal for Parasitology 20, 225-242.

MONTGOMERY, S. S. J. \& MONTGOMERY, W. I. (1989). Spatial and temporal variation in the infracommunity structure of helminths of Apodemus sylvaticus (Rodentia: Muridae). Parasitology 98, 145-150. MORRIS, P. (1972). A review of mammalian age determination methods. Mammal Review 2, 69-104.

o'sullivan, H. M., SMALl, C. M. \& FAirley, J. s. (1984). A study of parasitic infestations in populations of small rodents (Apodemus sylvaticus and Clethrionomys glareolus) on Ross Island, Killarney. Fournal of Life Sciences Royal Dublin Society 5, 29-42.

Poulin, R. (1993). The disparity between observed and uniform distributions: a new look at parasite aggregation. International Fournal for Parasitology 23, 937-944.
ROHLF, F. J. \& SOKAL, R. R. (1995). Statistical Tables.

W. H. Freeman \& Company, San Francisco.

SHELdON, B. C. \& VERHULST, s. (1996). Ecological immunology: costly parasite defences and trade-offs in evolutionary ecology. Trends in Ecology and Evolution 11, 317-321.

TENORA, F. \& MEszaros, F. (1975). Nematodes of the genus Syphacia Seurat, 1916 (Nematoda) - parasites of rodents (Rodentia) in Czechoslovakia and Hungary. Acta Universitatis Agriculturae 23, 537-554.

Washington, H. G. (1984). Diversity, biotic and similarity indices. A review with special relevance to aquatic ecosystems. Water Research 18, 653-694.

WIGER, R., BARUS, V. \& TENORA, F. (1978). Scanning electron microscopic studies on four species of the genus Syphacia (nematoda, Oxyuridae). Zoologica Scripta 7, 25-31.

Wilson, K. \& GRENFELl, B. T. (1997). Generalized linear modelling for parasitologists. Parasitology Today 13, 33-38.

ŻARNOWSKI, E. (1955). Parasitic worms of forest micromammalians (Rodentia and Insectivora) of the environment of Puławy (district Lublin). I. Cestoda. Acta Parasitologica Polonica 3, 279-343. 